\title{
STUDY OF THYROID HORMONE RECEPTORS EXPRESSION IN ABDOMINAL VISCERAL ADIPOCYTES OF OBESE VERSUS LEAN SUBJECTS Mohammad Hamed ${ }^{1}$, Manal AbuShady ${ }^{1}$, Mohammad Hassan ${ }^{2}$, Hanan Ali ${ }^{1}$ and Aliaa Algarhi ${ }^{1}$
}

${ }^{1}$ Departments of Internal Medicine \& Endocrinology and ${ }^{2}$ General Surgery, Faculty of Medicine, Ain Shams University, Cairo, Egypt.

.Corresponding Author: Aliaa Saber Ibrahim Wahba

Mobile: 01022630383

E-mail:

rashaedahmed341nhi@gmial.com

Received : $11 / 5 / 2020$

Accepted: 9/6/2020

Online ISSN: 2735-3540

\begin{abstract}
:
Background: Thyroid hormones are known to help in weight loss by stimulating metabolism, and they can help decrease cholesterol too. The activity of these hormones is regulated by chemicals called hormone receptors. Selective activation of these receptors may be able to effectively treat obesity, hypercholesterolemia; really a novel way of looking at obesity.
\end{abstract}

Aim of work: To measure the expression levels of thyroid hormone receptors in adipocytes of obese patients versus lean subjects, pointing out the effect of obesity on thyroid receptors and that of thyroid on burning fat and in turn forming an idea about thyroid regulatory status.

Patients and Methods: Case control study .Visceral adipose tissue samples will be provided from patients undergoing elective abdominal surgery. This study will be conducted on two groups: Group ob: comprises 20 obese subjects (BMI $>30 \mathrm{~kg} / \mathrm{m} 2)$

Group In: comprises 20 lean subjects $\left(B M I<25 \mathrm{~kg} / \mathrm{m}^{2}\right)$.

Results: Comparison between obese and lean groups regarding THR expression level in visceral adipocytes, it was statistically higher in the lean group. Correlation of THR expression in visceral adipocytes with TSH was highly significant and positive. The correlation of THR expression in visceral adipocytes was inversely with BMI, waist circumference, age, fasting blood glucose and fasting plasma insulin.

Conclusion: Thyroid hormone receptor expression level in visceral adipocytes decreased with age, fat belly, insulin resistance, dyslipidemia in the presence of high thyroid hormones in blood. Opposite to decreased TSH level in the blood according to our results, suggesting a role for adipocytes in the regulation of TSH and thyroid hormones.

Keywords: obese, lean, thyroid stimulating hormone; thyroid hormone receptor; body mass index.

\section{INTRODUCTION:}

Some studies have found that thyroid disorders may lead to obesity; whereas recent study shows that in some cases, obesity is the one that may cause thyroid disorder. Obesity inflames the thyroid leading to potentially lifelong thyroid problems if the weight is not lost ${ }^{(1)}$.

Thyroid hormones are known to help in weight loss by stimulating metabolism, and they can help decrease cholesterol too. The activity of these hormones is regulated by chemicals called hormone receptors. Selective activation of these receptors may be able to effectively treat obesity, hypercholesterolemia; really a novel way of looking at obesity ${ }^{(2)}$.

Thyroid hormone receptors are encoded by two genes, designated alpha and beta. Like other members of the nuclear receptor 
super family, they encapsulate three functional domains: a transactivation domain, a DNA-binding domain and a ligand-binding and dimerization domain ${ }^{(3)}$.

Study of thyroid hormone receptors expression in abdominal visceral adipocytes of obese versus lean subjects

Thyroid hormone receptors differ in tissue distribution and physiological response. Receptor- $\alpha$ seems to be more important in regulating heart rate while receptor- $\beta$ is involved in cholesterol lowering and metabolism. Development of $\beta$-selective thyromimetics and improved understanding of their actions is an important pharmacological and biomedical issue for treatment of obesity and elevated cholesterol level $^{(4)}$.

Tyroid hormone plays important roles in the development and function of brown and white adipose tissue, also stimulates adipocyte proliferation and fat cell cluster formation. Both $\mathrm{TR} \alpha$ and $\mathrm{TR}^{\beta}$ are expressed in Ob17 preadipocytes. Studies have shown that thyroid hormone is an obvious adipogenic factor in adipose differentiation. T3 plays important roles in regulating basal oxygen consumption, fat stores, lipogenesis, and lipolysis ${ }^{(5)}$.

\section{AIM OF THE WORK:}

To measure the expression levels of thyroid hormone receptors in adipocytes of obese patients versus lean subjects, pointing out the effect of obesity on thyroid receptors and that of thyroid on burning fat and in turn forming an idea about thyroid regulatory status.

\section{PATIENTS AND METHODS:}

\section{Participants and study design:}

Case control study,Visceral adipose tissue samples will be provided from patients undergoing elective abdominal surgery. All subjects were fully informed of the aim, nature, and risks of the study prior to giving written informed consent. This study will be conducted on two groups: Group obese: comprises 20 obese subjects (BMI $>30 \mathrm{~kg} / \mathrm{m} 2$ ). Group lean: comprises 20 lean subjects $(\mathrm{BMI}<25 \mathrm{~kg} / \mathrm{m} 2)$.

Exclusion criteria: Those who are less than 20 years old. Hypothyroid or hyperthyroid (history or TSH greater than 5.0 or less than $0.4 \mathrm{miU} / \mathrm{L}$ ) or receiving thyroid supplementation. Type 1 Diabetes Mellitus. Liver disease or ALT serum level greater than two fold the upper laboratory reference limit. Renal insufficiency or estimated creatinine clearance less than or equal to $50 \mathrm{~mL} / \mathrm{min}$ (Cockcroft method).History of illicit drug or alcohol abuse within the last 5 years; current use of drugs (by history) or alcohol (CAGE greater than 3) Psychiatric conditions or behavior that would be incompatible with safe and successful participation in this study. Pregnancy/breastfeeding. Cardiac Failure.

Subjects will be submitted to the following: Full medical history. Clinical examination and Anthropometric measures including body weight, height, body mass index and waist circumference. Laboratory investigations including: Thyroid profile: TSH, FT3, FT4.Fasting blood glucose, fasting insulin level. Total lipid profile. Real-time qPCR of thyroid hormone receptors expression in abdominal visceral fat needle biopsies.

Weight was measured in light clothing without shoes after emptying bladder. Height was measured as the distance from the top of the head to the bottom of the feet (no shoes) using a fixed stadiometer. BMI was calculated as the weight $(\mathrm{kg})$ divided by the square of the height $(\mathrm{m})$. The subjects were divided according to the BMI into obese (those with BMI $>30 \mathrm{~kg} / \mathrm{m} 2$ ) and nonobese subjects (those with $\mathrm{BMI}<25 \mathrm{~kg} / \mathrm{m} 2$ ). 


\section{THR in Obesity:}

Waist circumference $(\mathrm{cm})$ was taken with a tape measure as the point midway between the costal margin and iliac crest in the mid-axillary line with the subject bared, standing and breathing normally (Bluher et al., 2006). The study involved 20 obese participants undergoing gastric bypass surgery; 20 lean participants undergoing elective abdominal surgery (cholecystectomy) served as the control group. All participants provided informed, written consent, and the protocol was approved by the local Ethics Committee.

\section{Specimen Collection:}

After 12 hours overnight fasting $6 \mathrm{ml}$ of venous blood were collected by venopuncture, using sterile plastic syringe. One $\mathrm{ml}$ of the collected blood was taken in a fluoride containing tube and then centrifuged and the separated serum used immediatlely for the assay of fasting blood glucose level (by glucose oxidase method). $2 \mathrm{ml}$ of the collected blood was allowed to clot and then centrifuged and the separated plasma was kept frozen and stored at $-20^{\circ} \mathrm{C}$ for the assay of the lipid profile (total cholesterol, HDL and TG), thyroid profile and insulin level.

\section{Adipose tissue biopsy samples:}

At baseline, adipose tissue specimens obtained from visceral fat depots $(2-3 \mathrm{~g})$ were collected during abdominal surgery in RNA-Later (Ambion Inc., Applied Biosystems, Austin, TX, USA), and stored at $-80^{\circ} \mathrm{C}$ for total RNA extraction.

\section{Adipocyte isolation}

Mature adipocytes were isolated as described by Grohmann. The adipose tissue was washed thrice in Hank's balanced salt solution, cut into 1-mm3 slices and digested with $3 \mathrm{ml}$ of $4 \mathrm{mgml}$ type II collagenase in Hank's balanced salt solution for $60 \mathrm{~min}$ at 37 oC. Fragments of the tissue still remaining after this treatment were removed with forceps. The mature adipocytes were separated from the stromal fraction by centrifugation at $90 \mathrm{xg}$ for $3 \mathrm{~min}$ and were carefully transferred into a sterile Eppendorf tube.

\section{Total RNA isolation and cDNA preparation:}

Total RNA was isolated using a mixed protocol: Trizol and RNeasy Midi Kit (Qiagen, Hilden, Germany) to obtain a larger amount of purified RNA that was quantified by measuring absorbance at 260 and 280 nm. RNA integrity was then checked by visual inspection of the two ribosomal RNAs, $18 \mathrm{~S}$ and $28 \mathrm{~S}$, on $1 \%$ agarose gel. The average yields of total RNA were $10 \pm 1 \mathrm{ugg}$ 1 of the adipose tissue. The isolated RNA was stored at $-80^{\circ} \mathrm{C}$ until quantification of the target mRNAs. For first-strand cDNA synthesis, $1 \mathrm{mg}$ of total RNA was reversetranscribed in 20-ul volume using random hexamers as primers, according to the manufacturer's instructions (First strand cDNA Synthesis Kit for reverse transcription (RT)-PCR, AMV, Roche, Indianapolis, IN, USA).

\section{Relative quantification of quantifycation of THR gene expression:}

The relative quantification of mRNAs was performed by real-time PCR using a Light-Cycler instrument (Roche Diagnostics, Mannheim, Germany).Gene-specific primer were designed in our laboratory.

HPRT mRNA was used for sample normalization. A volume of $1 \mathrm{ml}$ of cDNA was increased to a final volume of $20 \mathrm{ml}$ in a glass capillary containing $1 x$ Light-CyclerFastStar DNA Master SYBR Green I mix (Roche Diagnostics), 0.3uM of primers for THR. PCR was performed with $10 \mathrm{~min}$ of initial denaturation and then 40 cycles with $10 \mathrm{~s}$ at $95^{\circ} \mathrm{C}$ (denaturation), $7 \mathrm{~s}$ at $58^{\circ} \mathrm{C}$ (annealing) and $13 \mathrm{~s}$ at $72^{\circ} \mathrm{C}$ (extension). The last cycle was performed at $40^{\circ} \mathrm{Cfor} 15 \mathrm{~s}$. Fluorescent data were acquired at the end of each extension phase. After amplification, a 
melting curve analysis from 65 and $95^{\circ} \mathrm{C}$ with a heating rate of $0.1^{\circ} \mathrm{Cs}-1$ with a continuous fluorescence acquisition was constructed.

To construct standard curves for each gene, total RNA from six control individuals were pooled. In brief, after RNA reverse transcription of the pool sample, the cDNA was diluted into a three-fold serial dilution (1:3-1:27) and both genes (target and reference) were amplified in triplicate. The standard curve was used to assess PCR efficiency. Standard curves were accepted only if the slope for each gene was approximately -3 with an $r$-value $>0.98$. Each cDNA was quantified in triplicate. For the relative quantification of samples, the 'Light-Cycler Relative Quantification Software' (Roche Diagnostics, Roche Applied Science, Mannheim, Germany) was used. Results were expressed as the targetreference ratio of each sample, normalized by the target- reference ratio of the calibrator. The calibrator used for each quantification was the sample with a dilution of 10-3 used in the standard curve. In the present data, the coefficient of variation in measurements for the target gene in each sample was $<10 \%$.We used HPRT as the reference gene because its expression was found to be relatively stable in different adipose tissue depots and showed no systematic differences between cases and controls $^{(6)}$.

Study of thyroid hormone receptors expression in abdominal visceral adipocytes of obese versus lean subjects

\section{Statistical analysis:}

Data were collected, revised, verified and then edited on personal computer. Data were then statistically analyzed using SPSS statistical package version 12. All data were expressedas means \pm standard deviations (SD) or percentages.

\section{The following tests were done:}

The Student's $\mathrm{t}$ test for independent samples., $\mathrm{X}^{2}=$ Chi-Square test., Pearson's correlation coefficient (r). Stepwise Regression Analysis: to determine the most constant independent variable in relation to a dependent variable. The significance of the results were assessed in the form of $\mathrm{P}$ value differentiated into: Non significant (NS) when $\mathrm{P}>0.05$. Significant (S) when $\mathrm{P}<0.05$.Highly significant (HS) when $\mathrm{P}<0.01$.

\section{RESULTS:}

The present study was conducted on 40 subjects who were selected from operating theatre of surgical departments, Ain Shams University hospital. All subjects were between 30 and 60 years old. Subjects with organ failure and secondary causes of diabetes were excluded.

\section{They were divided into two groups:}

Group 1: Included 20 obese patients. There were 12 males (73.3\%) and 8 females (26.7\%). Their ages with a mean of (52.3 \pm 6.6$)$. Those with $\mathrm{BMI} \geq 30$ were considered obese, while those with $\mathrm{BMI} \leq$ 25 were considered lean. Their BMI with a mean of (33.7 \pm 5.4$)$.

Group 2: Included 20 lean subjects as a control group. They were age and sex matched included 10 males $(50 \%)$ and 10 females $(50 \%)$. Their ages with a mean of $(38.2 \pm 14.5)$. Their BMI with a mean of $(23$ \pm 1.3 ). The two main groups (obese versus lean) were matched as regard gender, age with no statistical significance difference.

Body mass index: A comparison between diabetics and non-diabetics regarding BMI showed that there was no statistical significant difference with $(\mathrm{P}>0.05)$. A comparison between obese and lean of both groups regarding BMI showed that there is highly statistical significant 
difference between the obese and lean of both groups regarding BMI $(\mathrm{P}<0.001)$.

Waist Circumference: A comparison between the obese $(\mathrm{N}=20)$ with a mean of $(113 \pm 15.5 \mathrm{~cm})$ and the lean $(\mathrm{N}=20)$ with a mean of $(85 \pm 6.7 \mathrm{~cm})$ of both groups regarding the waist circumference showed that the difference was highly statistically significant. A comparison between male and female regarding waist circumference showed that the difference was not statistically significant. Male $(\mathrm{N}=22)$ with a mean of $(105.3 \pm 89 \mathrm{~cm})$ and female $(\mathrm{N}=18)$ with a mean of $(101.5 \pm 16 \mathrm{~cm})$.
Lipid Profile: A comparison between the obese and the lean of both groups regarding the lipid profile showed that there was no statistically significant difference regarding TG and HDL. Total cholesterol was higher in obese $(215.6 \pm 30.9 \mathrm{mg} / \mathrm{dl})$ than lean (175.6 \pm 26.7$)$. This difference was statistically significant. LDL was higher in obese $(138.5 \pm 28.3)$ than lean $(106.8 \pm 19.8)$. This difference was statistically significant.

Study of thyroid hormone receptors expression in abdominal visceral adipocytes of obese versus lean subjects

Table 1: Clinical and Metabolic Measurements:

\begin{tabular}{|l|lll|}
\hline Measurements & Obese & Lean & P-value \\
\hline Subjects & 20 & 20 & \\
Sex (F/M) & $8 / 12$ & $10 / 10$ & $>0.05$ \\
Age $($ years) & $52.3 \pm 6.6$ & $43.8 \pm 10.3$ & $>0.05$ \\
BMI(Kg/m $\left.{ }^{2}\right)$ & $33.7 \pm 5.4$ & $23 \pm 1.3$ & $<0.001$ \\
WaistCir(cm) & $113 \pm 15.5$ & $85 \pm 6.7$ & $<0.001$ \\
FPI (mIU/L) & $20.7 \pm 25$ & $15.4 \pm 16$ & $<0.05$ \\
Chol (mg/dl) & $215 \pm 30$ & $175.6 \pm 26.7$ & $<0.05$ \\
TG (mg/dl) & $175 \pm 84$ & $124 \pm 67$ & $>0.05$ \\
HDL & $43.5 \pm 8.9$ & $43.8 \pm 10.3$ & $>0.05$ \\
LDL & $138.5 \pm 28$ & $106.8 \pm 19.8<0.05$ \\
TSH (uIU/ml) & $1.4 \pm 0.3$ & $2 \pm 1.1$ & $<0.05$ \\
FT3(ng/dl) & $3.8 \pm 1.0$ & $3.5 \pm 0.9$ & $<0.05$ \\
FT4 & $10.7 \pm 4.3$ & $9.6 \pm 4.7$ & $<0.05$ \\
THR & $1.1 \pm 0.3$ & $1.9 \pm 0.4<0.001$ \\
\hline
\end{tabular}

Abbreviations: BMI, body mass index; DBP, F, female; FGP, fasting plasma glucose; FPI, fasting plasma insulin; FT3, free triiodo-thyronine; $\mathrm{FT}_{4}$, free tetraiodotyronine; HDL-chol., highdensity lipoprotein-cholesterol; M, male; PG, plasma glucose; PI, plasma insulin; T-chol., Tcholesterol; TG, triglyceride; TSH, thyroid-stimulating hormone.

Table 2 Thyroid hormone receptor (THR) expression in visceral adipocytes

\begin{tabular}{|l|l|l|l|}
\hline THR MEASUREMENTS & & & P-value \\
\hline Obese/lean & $1.1 \pm 0.3$ & $1.9 \pm 0.4$ & $<<<0.001$ \\
\hline Male/female & $1.8 \pm 0.6$ & $1.75 \pm 0.9$ & $>0.05$ \\
\hline DM/non-DM & $1.3 \pm 0.4$ & $1.8 \pm 0.5$ & $<0.05$ \\
\hline
\end{tabular}

Abbreviations: HPRT, hypoxantine-phosphorybosyl-transferase; T2DM, type 2 diabetes.THR expression data are given as ratio of target gene to reference gene (HPRT).

A comparison between the obese diabetics and the obese non-diabetics regarding lipid profile showed that there was no statistically significant difference regarding total cholesterol, TG, HDL and LDL.

A comparison between the lean diabetics and the lean non-diabetics regarding lipid profile showed that there was 
no statistically significant difference regarding total cholesterol, TG, HDL and LDL.

Insulin Level: A comparison between the obese patients (group 1) and the lean

\section{THR in Obesity:}

subjects (group 2) regarding insulin level showed that it was higher in obese $(20.7 \pm 25 \mathrm{mIU} / \mathrm{L})$ than lean $(15.4 \pm 16)$. these differences were statistically significant $(\mathrm{P}<0.05)$.

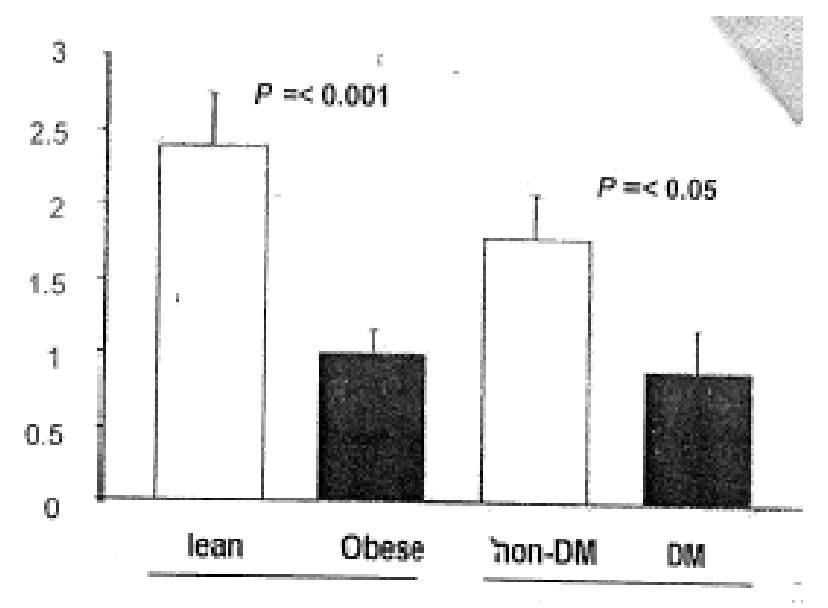

Figure 1. Mean ${ }^{ \pm}$s.d.THR protein expression in visceral adipocytes.

Thyroid hormone profile :A comparison between the obese patients (group 1) and the lean subjects (group 2) regarding the thyroid hormone profile showed that the TSH was significantly higher in the lean group $(2.0 \mathrm{mIU} / \mathrm{L} \pm 1.1)$ than the obese group $(1.4 \pm 0.3) \quad(\mathrm{P}<0.05)$. A comparison between the obese and the lean regarding the FT3 showed that FT3 was higher in the obese (3.8ng/dl \pm 1.0$)$ than the lean $(3.5 \pm 0.9)$.

This difference was statistically significant $(\mathrm{P}<0.05)$. A comparison between the obese and the lean regarding the FT4 showed that the FT4 was higher in the obese $(10.7 \mathrm{ng} / \mathrm{dl} \pm 4.3)$ than the lean $(9.6 \pm 4.7)$. This difference was statistically significant $(\mathrm{P}<0.05)$. A comparison between the diabetics and the non-diabetics of both groups regarding the thyroid profile showed that there was no statistically significant difference $(\mathrm{P}>0.05)$.

Thyroid hormone receptor (THR) expression: A comparison between the obese patients (group 1) and lean subjects (group 2) regarding thyroid hormone receptors expression(THR) in visceral adipocytes showed that the difference was in obese group $(1.1 \pm 0.3 \mu \mathrm{g} / \mathrm{dl})$ and lean group $(1.9 \pm 0.4 \mu \mathrm{g} / \mathrm{dl}) \quad$ with high statistical significant difference $(\mathrm{P}<0.001)$.

A comparison between the obese diabetics with a mean of $(2.4 \pm 0.4)$ and obese non-diabetics group with a mean of $(1.3 \pm 0.2)$ of both groups regarding THR expression showed that this difference was statistically highly significant $(\mathrm{P}<0.001)$.

Also, the comparison between male and female regarding THR expression showed that there was no statistically significant difference between both with a mean of $(1.8 \pm 0.6)$ for the male and $(1.75 \pm 0.9)$ for the female.

By using Pearson's coefficient correlation, it was found that the THR expression in visceral adipocytes level was negatively correlated with age $(\mathrm{r}=-0.4)$, the waist circumference $(\mathrm{r}=-0.6)$, FBG $(\mathrm{r}=-0.4)$ and FPI $(\mathrm{r}=-0.4)$ and BMI $(\mathrm{r}=-0.6)$ and the correlation was statistically significant.

The THR expression in visceral adipocytes positively correlated with $\mathrm{TSH}(\mathrm{r}=0.5)$, with high statistical 
significance $(\mathrm{P}<0.001)$. Whereas the correlation between the THR expression in visceral adipocytes and the total cholesterol level $(\mathrm{r}=-0.3)$, the LDL $(\mathrm{r}=-0.1)$ was negative with no statistical significance Whereas the correlation between the THR expression in visceral adipocytes and the total cholesterol level $(\mathrm{r}=-0.3)$, the LDL $(\mathrm{r}=-$ $0.1)$ was negative with no statistical significance.

For determination of the most important predictor of THR expression in visceral adipocytes among the studied parameters, a stepwise regression analysis was done and revealed that TSH level is the most important predictor of THR expression level in visceral adipocytes while BMI is the predictor in an inverse manner.

\section{DISCUSSION:}

As lipid metabolism is closely associated with a number of health problems, regulation of adipocytes represents an area of emerging interest. So far, TR has been implicated as a major factor in the regulation of the development and function of adipose tissue ${ }^{(5)}$.

Triiodothyronine increases the accumulation of lipid droplets and the expression of lipogenic enzyme in 3T3-L1 adipocytes. Moreover, the TR isoform is predominantly expressed in adipocytes, suggesting that TR seems to be involved in a complex process of lipid accumulation in adipocytes. These results are consistent with our finding that FT3, FT4 concentrations are higher in obese than in lean individuals.

The major findings of our study was congruent with that of Nannipieri: 1 . the expression levels of TSHR and TRa1 are higher in SAT than in VAT; 2. in both adipose tissue depots, TSHR and, marginally, TRa1 is reduced in obesity (and in proportion to the degree of obesity) regardless of the glucose tolerance status; 3 . serum TSH and FT3 concentrations are higher in obese than in lean individuals; and 4. after major weight loss.

While in our study TSH correlated negatively with the degree of obesity in the face of high concentrations of FT3and FT4, contradictory to higher TSH levels among slightly overweight euthyroid individuals thereby resulting in a positive correlation between TSH and the progressive increase in weight with time ${ }^{(7) .}$

Whereas, in our study the THR expression in visceral adipocytes in the diabetic subgroup was scant in comparison with the non-diabetic subgroup. TSHR and TRal expression in SAT increases significantly, with a concomitant reduction in circulating TSH and FT3 levels ${ }^{(6)}$.

Many previous studies have reported increased TSH and FT3 levels in obese, clinically euthyroid patients ${ }^{(8)}$ our series contradicts these findings. Furthermore, BMI has been negatively associated with serum FT4 that was not confirmed by our study.

Study of thyroid hormone receptors expression in abdominal visceral adipocytes of obese versus lean subjects

On the other hand, this study is one of the few investigations that have unequivocally shown that weight loss leads to a reduction in both TSH and FT3 levels ${ }^{(9)}$.

Several explanations have been proposed to account for the influence of obesity on thyroid hormones. One suggests that the increased TSH level could reflect pituitary adaptation to increased adiposity through adipokines. In morbidly obese patients with subclinical hypothyroidism, bariatric surgery led to changes in obesityrelated adipokines believed to influence the synthesis and secretion of thyroid hormones (10).

However, in a recent study from ${ }^{(9)}$ the direct relationship between 24-h mean concentrations of TSH and leptin in 
euthyroid obese patients was lost after adjusting for fat mass, suggesting that other mechanisms modulate TSH concentrations in morbidly obese patients. Another explanation is that the thyroid hormone profile of the obese individuals reflects pituitary resistance to thyroid hormones, with a variable degree of secondary impairment of thyroid hormone peripheral metabolism ${ }^{(11) .}$

Moreover, it has also been reported that there is an inverse correlation between free thyroxine (FT4) values and body mass index (BMI), even when FT4 values remain in the normal range. Another potential cause of increased blood concentration of TSH may be the high levels of leptin, found in obese subjects ${ }^{(12)}$.

The reported high conversion rate of $\mathrm{T} 4$ to T3 in obese patients has been also interpreted as a defense mechanism, capable of counteracting the accumulation of fat by increasing the energy expenditure ${ }^{(20)}$, basal metabolic rate and the total energy expenditure, being in fact positively related to the levels of total T3 and FT3. Leptin, a hormone produced by adipocytes, also alters the activity of deiodinases, thus promoting the conversion of $\mathrm{T} 4$ to $\mathrm{T} 3{ }^{(13)}$.

Another mechanism claimed to explain the high values of T3 and FT3 has been related to the fact that the expressions of both TSH and thyroid hormones are reduced in adipocytes of obese subjects as compared to individuals of normal weight. This would prompt a decreased tissue responsiveness to circulating thyroid hormones and would also explain the consequent increased compensatory secretion of TSH and FT3 in an attempt to force the state of peripheral resistance ${ }^{(6) \text {. }}$

However, information on the tissue expression of genes encoding for TSH and thyroid hormone receptors, and activity of the respective proteins in relation to body weight or diabetes is scarce. TSHRs have been found in rats and in human adipose tissues.

In the post-neonatal period and in children, an important lipolytic effect of TSH on adipose tissue has been described, rapidly declining with increasing age (14). This result was in accord with our study.

Other studies have shown that TSH has a role in the regulation of several adipokines synthetized in mature adipocytes and in the induction of preadipocyte proliferation and differentiation.

Our study is addressing the expression of THR in adipose tissue obtained from obese patients, and evaluating the effect of obesity on these receptors. The findings, of a reduced expression which reverses in lean individuals and those of reciprocal changes in expression and circulating TSH and FT3 concentrations, suggest a role of obesity, and the expanded adipose mass in particular, in regulating THRs and, indirectly, also in circulating $\mathrm{TSH}$, rather than a contribution of thyroid axis to the causation of obesity. Thus, one could speculate that hypertrophy changes the cellular phenotype of the adipocyte, reducing the expression of these receptors in much the same way as with adiponectin receptors or insulin sensitivity $^{(15)}$

It is of interest that, the presence of diabetes had no effect on the thyroid hormone system independently of obesity ${ }^{(15)}$.This result was not consistent with our findings .Although a low T3 syndrome has been reported in some patients with decompensated diabetes ${ }^{(16)}$, adipose tissue mass has not been taken into account.

Our findings were related to diabetes with no separate effect on obesity and metabolic parameters that were significantly improved in lean individuals.

In obese individuals, THR is less expressed than in lean individuals in the face of higher plasma TSH levels; both these changes are reversed in lean individuals. 
There was a link and positive correlation between high insulin levels and obesity with or without type 2 diabetes. The role of insulin in lipogenesis and adipocyte differentiation. There was a link and positive correlation between high insulin levels and obesity with or without type two diabetes. The role of insulin in lipogenesis and adipocyte differentiation. The changes regarding the expression of thermogenesisrelated genes in diet-induced obesity can be related to the methylation status of their regulatory regions.

However, no differences in methylation between normal weight and obese subjects, between VAT, visceral adipose tissue and SAT, subcutaneous tissue and between tissues with high vs. low expression of a given gene. In addition, the methylation level of the investigated genes was not related to the level of their expression ${ }^{(17) .}$

Adipose tissues of obese individuals are characterized by a decreased expression of the key genes involved in the activation of thermogenesis. On that basis we propose that adipose tissue of obese individuals might be less reactive to both hormonal and adrenergic stimuli and, therefore, less likely to activate thermogenesis than in lean subjects.

Mutations within NLS, nuclear localization signal and NES, nuclear export signal motifs affect nuclear shuttling activity, and propose that THR mislocalization contributes to the development of obesity, cancer and resistance to thyroid hormone syndrome ${ }^{(18) .}$

All body fat is not created equal in terms of associated health risks. Visceral fat is strongly linked to metabolic disease and insulin resistance, and an increased risk of death, even for people who have a normal body mass index. Subcutaneous fat doesn't carry the same risks ${ }^{(19) .}$

Two adipose tissues have been identified: white and brown adipose tissues with different phenotype, function and regulation.BAT thermogenesis explains the essential part played by thyroid hormone in energy homoeostasis and adaptation to cold. Stimulation of BAT in adults, specifically through thyroid-hormone-mediated pathways, is a promising therapeutic target for obesity ${ }^{(20) \text {. }}$

In conclusion, Thyroid hormone receptor expression level in visceral adipocytes decreased with age, fat belly, insulin resistance, dyslipidemia in the presence of high thyroid hormones in blood. Opposite to decreased TSH level in the blood according to our results.

\section{REFERENCES:}

1. Radetti G,KleonW, Buzi F, Crivellaro C, Pappalardo L, Di Iorgi $\mathrm{N}$ and Maghnie M (2008): Thyroid Function and Structure Are Affected in Childhood Obesity. J ClinEndocrin\&Metab, 93,4749-4754.

2. Grover GJ, Mellström K, Ye L, Malm J (2003): Selective thyroid hormone receptor$\beta$ activation: A strategy for reduction of weight, cholesterol, and lipoprotein (a) with reduced cardiovascular liability. Proc Natl AcadSci U S A, 17, 10067-10072.

3. Zhang J, Lazer MA (2000): The mechanism of action of thyroid hormones. Annu Rev Physiol., 62,439-466.

4. Bleicher L, Aparicio R, Nunes $F$ M, Martinez L(2008): Structural basis GC-1 selectivity for thyroid hormone receptor isoforms. BMC Structural Biology, 8, 1186/1472-6807-8.

5. Yen P M (2001): Ysiological and Molecular Basis of Thyroid Hormone Action Physiol. Rev, 81, 1097-1142.

6. Nannipieri M,Cecchetti F, Anselmino M,Camastra S, Niccolini P, Lamacchia M, Rossi M, Iervasi $\mathrm{M}$ and $\mathrm{E}$ Ferrannin $\mathrm{E}$ (2009): Expression of thyrotropin and thyroid hormone receptors in adipose tissue of patients with morbid obesity and/or type 2 diabetes: effects of weight loss. 
International Journal of Obesity, 33, 10011006.

7. Fox CS, Pencina MJ, D'Agostino RB, Murabito JM, SeelyEW, PearceEN, Vasan RS (2008): Relations of thyroid function to body weight: cross-sectional and longitudinal observations in a community-based sample. Arch Intern Med,168,587-592.

8. De Pergola D, Ciampolillo A, Paolotti S, Trerotoli P, Giorgino R. Free triiodothyronine and thyroid stimulating hormone are directly associated with waist circumference, independently of insulin resistance, metabolic parameters and blood pressure in overweight and obese women. ClinEndocrinol 2007; 67: 265-269.

9. Camastra $S$, Manco $M$, Frascerra $S$, Iaconelli A, MingroneG,Ferrannini E (2009): Daylong pituitary hormones in morbid obesity: effects of bariatric surgery. Int J Obes, 33, 166-172.

10. Chikunguwo S, Brethauer S, Nirujogi V, Pitt T, Udomsawaengsup S, Chand B et al. (2007)Influence of obesity and surgical weight loss on thyroid hormone levels. SurgObesRelat Dis, 3, 631-635.

11. Krotkiewski M (2002): Thyroid hormones in the pathogenesis and treatment of obesity. Eur J Pharmacol, 440,85-98.

12. Aeberli I, Jung A, Murer SB,Wildhaber J, Wildhaber-Brooks J, Knopfli BH, Zimmermann MB (2010): During rapid weight loss in obese children, reductions in TSH predict improvements in insulin sensitivity independent of changes in body weight or fat. J Clin Endocrinol Metab,95, 5412-5418.

13. Longhi S and Radetti G (2013): Thyroid Function and Obesity. J Clin Res Pediatr Endocrinol, 5(1),40-44.
14. Janson A, Karlsson FA, Micha-Johansson G, Bolme P, Bro"nnega ${ }^{\circ}$ rd M, Marcus C. Effects of stimulatory and inhibitory thyrotropin receptor antibodies on lipolysis in infant adipocytes. J ClinEndocrinolMetab 1995; 80: 1712-1716.

15. Nannipieri $M$, Cecchetti $F$, Anselmino $M$, Camastra S, Niccolini P, Lamacchia M, Rossi $M$, Iervasi $M$ and $E$ Ferrannin $E$ (2009): Expression of thyrotropin and thyroid hormone receptors in adipose tissue of patients with morbid obesity and/or type 2 diabetes: effects of weight loss. International Journal of Obesity ,33, 10011006.

16. Mouradian M, Abourizk N. Diabetes mellitus and thyroid disease. Diabetes Care 1983; 6: 512-520.

17. Kurylowicz A, Jonas M, Lisik W, AgnieszkaWicik Z et al. (2015) .Obesity is associated with a decrease in expression but not with the hypermethylation of thermogenesisrelated genes in adipose tissues .Journal of Translational Medicine,13,31.

18. Zhang J, Roggero V, Allison L (2018): Nuclear import and Export of the thyroid hormone receptor. Vitamins and Hormones, Elsevier, 106, 45-66.,

19. Qiang G, Kong HW et al (2016): The obesity-induced transcriptional regulator TRIP-Br2 mediates visceral fat endoplasmic reticulum stress-induced inflammation. Nature Communications, 7,11378.

20. Bianco A and McAninch E (2013). The role of thyroid hormone and brown adipose tissue in energy homoeostasis. Lancet Diabetes Endocrinol, 1(3),250-258. 


\section{دراسة مستقبلات هورمون الغدة الدرقية في خلايا ده احشا البطن في البدناء مقارنة بالنجاف محمد سهر خامد و منال ابو شادى و محمد حسن و حنان علي و علياء الجارحي}

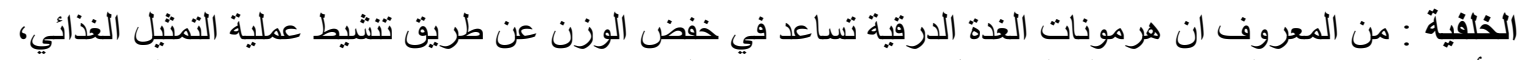

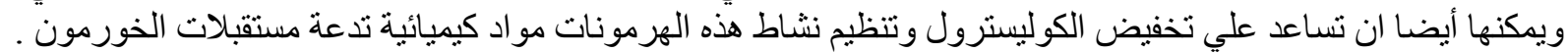

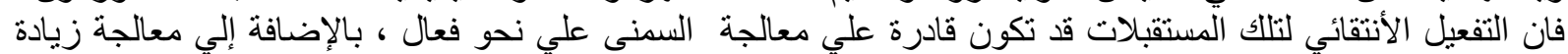
الدهون في الدم ، في الواقع وسيلة جديدة للنظر إلي السمنة.

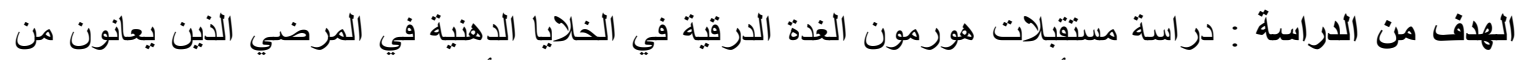

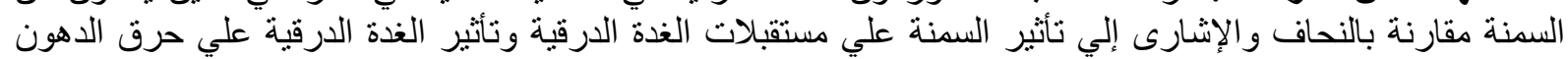

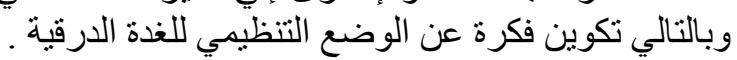

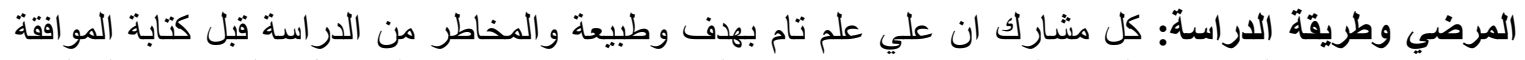

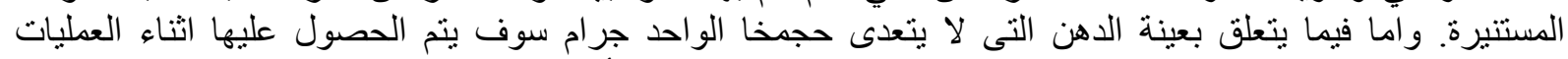

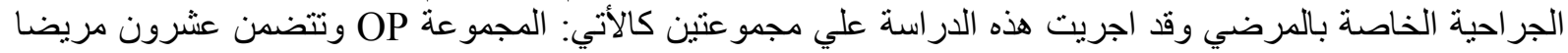

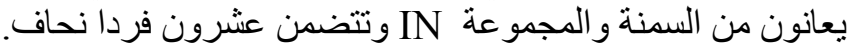

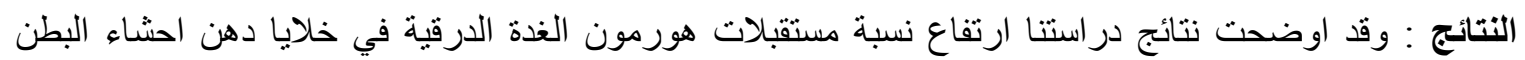

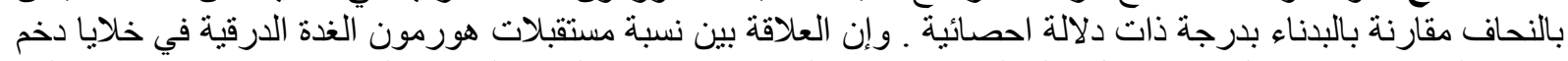

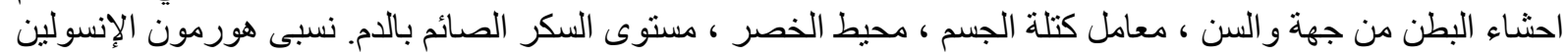
بالدم من جهة اخرى هي علاقة عكسية ذات دلاتلة دلألة احصائية.

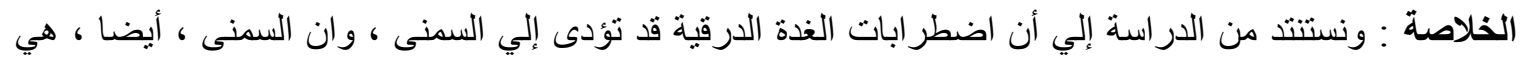

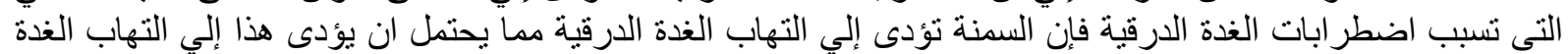

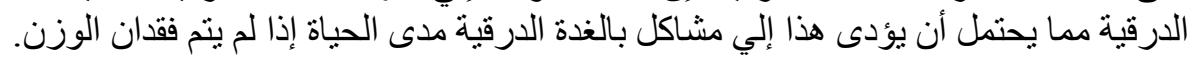

